\title{
Validation of an analytical technique, distribution, and risk assessment of aliphatic and polycyclic aromatic hydrocarbons in surface sediments of the coastal and selected estuaries of Sarawak
}

\author{
Ebenezer Aquisman Asare ${ }^{1,2}\left(\mathbb{D} \cdot\right.$ Zaini Bin Assim $^{1} \cdot$ Rafeah Wahi $^{1}$
}

Received: 7 March 2021 / Accepted: 26 August 2021

(C) Saudi Society for Geosciences 2021

\begin{abstract}
This study explains a validation of an analytical technique, monitoring, and risk evaluation of hydrocarbons in surface sediments of the coastal and selected estuaries of Sarawak, Malaysia. The performance of an analytical methodology was validated for the evaluation of hydrocarbons in coastal and estuaries sediment samples. After the clean-up and separation process, GC-FID and GC-MS were used to quantify aliphatic and polycyclic aromatic hydrocarbon extracts, respectively. The suggested methodology is able to measure aliphatic and polycyclic aromatic hydrocarbons in samples at lower concentrations for example $10 \mathrm{ng} / \mathrm{g}$. The precision of the technique was satisfactory as compared to $15 \%$ for most of the analytes. This method gives information concerning the distribution and characteristics of hydrocarbon contaminants in the coastal environment. In regard to monitoring and risk assessment, total $\mathrm{n}$-alkane concentrations $\left(\mathrm{C}_{10}-\mathrm{C}_{33}\right)$ varied from 96.63 to $367.28 \mathrm{ng} / \mathrm{g} \mathrm{dw}$. The lowest and highest $\mathrm{n}$ alkane content is observed at Santubong estuary (CZ10) and the coastal site CZ2, respectively. Simultaneously, the contents of $\sum$ PAHs varied from 12.54 to $21.20 \mathrm{ng} / \mathrm{g}$ dw. The highest $\sum$ PAH content is reported in the sediments of coastal site CZ8 (21.20 $\mathrm{ng} / \mathrm{g} \mathrm{dw})$, whereas the lowest content is recorded in the sediments of coastal site CZ3 (12.54 ng/g dw). The outcome of the risk assessment suggested that there is no risk in all the studied locations. The findings from this study will help to understand the sources and possible risks of hydrocarbons in the coastal and estuary settings, and provide information for safeguarding human health and aquatic bodies in the studied area.
\end{abstract}

Keywords Validation $\cdot$ Sediments $\cdot$ Petroleum hydrocarbons $\cdot$ Toxic equivalency factor $\cdot \mathrm{BaP}$ equivalent

\section{Introduction}

On account of the extensive distribution of oil contamination in the environment, the determination of petroleum-related environmental samples is remarkably significant. Petroleum contaminants cause wide harm to the estuary and coastal life, natural resources, and human health. Its make-up study permits the understanding of the fate and characteristics of

Responsible Editor: Amjad Kallel

Ebenezer Aquisman Asare aquisman1989@gmail.com

1 Faculty of Resource Science and Technology, Universiti Malaysia Sarawak, Kota Samarahan, Malaysia

2 Department of Nuclear Science and Applications, Graduate School of Nuclear and Allied Sciences, University of Ghana, AE1, Atomic, Accra, Ghana contaminants and the projection of the possible long-term effect of spilled oils on the environment. Over thousands of organic compounds can be found in petroleum. The development of feasible and reasonable analytical methods for constitutional analysis by gas chromatography-flame ionization (GC-FID) and GC-mass spectrometry detection (MS) in the determination of petroleum hydrocarbons is of great concern (Ramos et al. 2000; Wang et al. 2002; Hartmann et al. 2004; Basheer et al. 2005). These analytical methods permit the assessment and their relative pattern of each petroleum hydrocarbon in compounds of a complex mixture (Damas et al. 2009). Various steps are required for organic traces in complex matrices analysis. Fundamentally, the extract was cleanup and fractionated after extraction, summing it all, chromatography procedures are employed in the separation of the analytes. According to Song et al. (2002), using Soxhlet, mechanical shaking or stirring, and ultrasonic extraction serve as the basis by which petroleum contaminants are extracted from solid samples in the environment. Numerous techniques have 